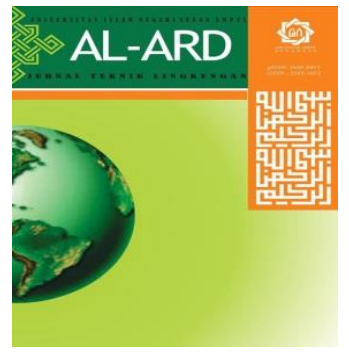

Al-Ard: Jurnal Teknik Lingkungan

Vol.5 No.2 - Maret 2020 (hal. 98-106)

http://jurnalsaintek.uinsby.ac.id/index.php/alard/index
Al-Ard:

Jurnal

Teknik Lingkungan

\title{
Analisis Timbulan Sampah Pasar Tradisional (Studi Kasus: Pasar Ujungberung, Kota Bandung) Mochammad Chaerul $^{1}$, Titara Puspita Dewi ${ }^{2}$
}

1,2Institut Teknologi Bandung, Indonesia $\underline{\text { m.chaerul@ftsl.itb.ac.id }}$

\begin{abstract}
Abstrak
Pasar Ujungberung merupakan salahsatu pasar tradisional di Kota Bandung yang aktivitas jual-belinya masih ramai dan berdampak pada kebutuhan pengelolaan sampah yang lebih baik. Agar dapat dilakukan pengelolaan sampah yang baik maka dibutuhkan data timbulan yang lebih presisi. Paper ini bertujuan untuk mengetahui timbulan sampah tersebut melalui pelaksanaan prosedur sampling sesuai dengan SNI selama 8 hari berturut-turut. Jumlah keseluruhan kios yang aktif digunakan untuk jual-beli adalah 565 kios dengan jumlah responden untuk sampling dan kuesioner sebanyak 85 kios. Rerata timbulan sampah tertinggi dan terendah masing-masing berasal dari kios makanan jadi (3,16 kg/hari) dan kios hasil bumi $(0,02 \mathrm{~kg} / \mathrm{hari})$. Berdasarkan unit yang mungkin berpengaruh pada timbulan sampahnya, maka secara rerata timbulan sampah perhari di Pasar Ujungberung adalah 0,464 kg/kios, 0,109 kg/m2 kios, 0,240 kg/ $\mathrm{karyawan,} \mathrm{0,047}$ $\mathrm{kg} / \mathrm{jam}$ operasional. Walaupun komposisi jenis sampah yang dihasilkan dari setiap kios berbeda, plastik, organik dan kertas merupakan tiga jenis sampah yang diprediksi dominan dihasilkan dari Pasar Ujungberung. Berdasarkan observasi lansung dan wawancara diketahui bahwa sebagian besar pedagang membuang sampahnya dengan menggunakan kresek plastik ke lokasi penampungan sampah terdekat. Data timbulan sampah yang diperoleh dari studi ini dapat digunakan untuk memprediksi timbulan sampah di pasar tradisional lain sehingga perencanaan pengelolaan sampah dapat dilakukan dengan lebih baik.
\end{abstract}

Kata Kunci: Timbulan sampah, komposisi, pasar tradisional, sampling

\begin{abstract}
Ujungberung market is one of traditional market in Bandung city having high business transaction and generates a significant solid waste to be managed properly. In order to establish a proper solid waste management, the reliable data on waste generation is crucially required. The paper aims to find the waste generation through performing waste sampling procedure based on Indonesian Standard for 8 days consecutively. There were total 566 stalls available in the market and 85 stalls were selected as respondents for sampling and questionnaire. The results showed that the highest and lowest average of waste quantity were generated by food stall ( $3.16 \mathrm{~kg} /$ day) and tuber stall $(0.02 \mathrm{~kg} /$ day), respectively. Based on units that may affect the waste quantity, the average daily waste generations are follows: 0,464 $\mathrm{kg} / \mathrm{stall}, 0,109 \mathrm{~kg} / \mathrm{m} 2$ area of stall, $0,240 \mathrm{~kg} /$ employee, $0,047 \mathrm{~kg} / \mathrm{hour}$ of stall operational. Although the waste composition generated from each stall may vary, the most dominant type of waste predicted to be generated in the market totally were plastic, organic, and paper, respectively. According to the field observation and the questionnaire, most of seller dispose of their waste using plastic bag to the nearest waste storage. The data of waste generation resulted from the study could be used to predict the generation for other traditional market for establishing a better planning of the waste management system.

Keywords: waste generation, composition, traditional market, sampling
\end{abstract}

\section{PENDAHULUAN}

Berdasarkan Undang-Undang No. 18 Tahun 2008 tentang Pengelolaan Sampah, sampah didefinisikan sebagai sisa kegiatan sehari-hari manusia dan/atau proses alam yang berbentuk padat. Berdasarkan sumbernya, sampah dapat diklasifikasikan menjadi sampah dari pemukiman, komersial, institusi, konstruksi dan pembongkaran bangunan, fasilitas umum, instalasi pengolahan limbah, industri, dan pertanian (Tchobanoglous, 1993). Pengelolaan limbah padat merupakan permasalahan di seluruh dunia dan menjadi semakin rumit seiring dengan pertumbuhan populasi, industrualisasi yang berdampak pada perubahan gaya hidup (Singh et al, 2011). 
Terdapat berbagai macam upaya daur ulang sampah untuk mengurangi potensi dampak negatif dan menghasilkan suatu produk yang lebih bernilai ekonomis (Pribadi, 2015, Ubaidillah et al., 2018, Sari, 2017, Nengse, 2017, Chaerul, 2019).

Pasar tradisional merupakan pasar yang dibangun dan dikelola oleh pemerintah, koperasi, atau swadaya masyarakat dengan tempat usaha skala kecil dengan proses jual beli melalui tawar-menawar. Pasar Ujungberung Bandung merupakan salah satu pasar tradisional tertua di Kota Bandung yang berlokasi di Jalan Jenderal Abdul Haris Nasution, Bandung. Jumlah kios di Pasar Ujungberung Bandung mencapai 691 kios dengan 565 kios aktif dan sisanya gudang.

Beberapa instrumen telah diusulkan untuk pengelolaan limbah padat rumah tangga. Agar instrumen tersebut dapat berjalan dengan lancar dan sukses maka sangat penting untuk menyelidiki faktor-faktor sosial yang mempengaruhi perilaku masyarakat selama penerapannya (Jones et al, 2010) dalam hal ini adalah perilaku para pedagang di pasar Ujungberung. Dengan adanya pengelolaan sampah pasar yang baik dapat menguragi jumlah sampah yang diangkut ke TPA. Berbagai studi menunjukkan bahwa 90\% dari pengelolaan limbah padat dengan sistem open dumping dan landfill yang tidak diperhitungkan dengan baik dapat menimbulkan masalah kesehatan masyarakat dan lingkungan (Sharholy et al, 2008). Mengingat berbagai macam dampak negatif yang bisa ditimbulkan, baik ke lingkungan maupun kesehatan masyarakat, maka diperlukan suatu sistem pengelolaan sampah pasar yang lebih baik (Aye \& Widjaya, 2006, Matsui et al., 2015, Sukresno et al., 2019, Hartono et al., 2015).

Studi ini bertujuan untuk mengetahui timbulan sampah secara detail yang dihasilkan dari setiap jenis pedagang yang ada di Pasar Tradisional Ujungberung, Kota Bandung melalui prosedur sampling berdasarkan SNI sehingga didapat data yang lebih akurat. Dengan tersedianya data timbulan yang lebih dapat dipercaya, penyusunan rencana perbaikan sistem pengelolaan sampahnya pun diharapkan akan lebih baik.

\section{METODE PENELITIAN}

Tahapan yang dilakukan pada penelitian ini meliputi kegiatan persiapan dan identifikasi awal, survei lapangan, sampling dan kuesioner, serta wawancara terhadap berbagai pihak yang terkait dengan pengelolaan persampahan di Pasar Ujungberung Bandung. Selain itu juga dilakukan pengumpulan data sekunder untuk bahan evaluasi terhadap data primer hasil sampling dan kuesioner. Untuk lebih jelas dapat dilihat pada Gambar 1.

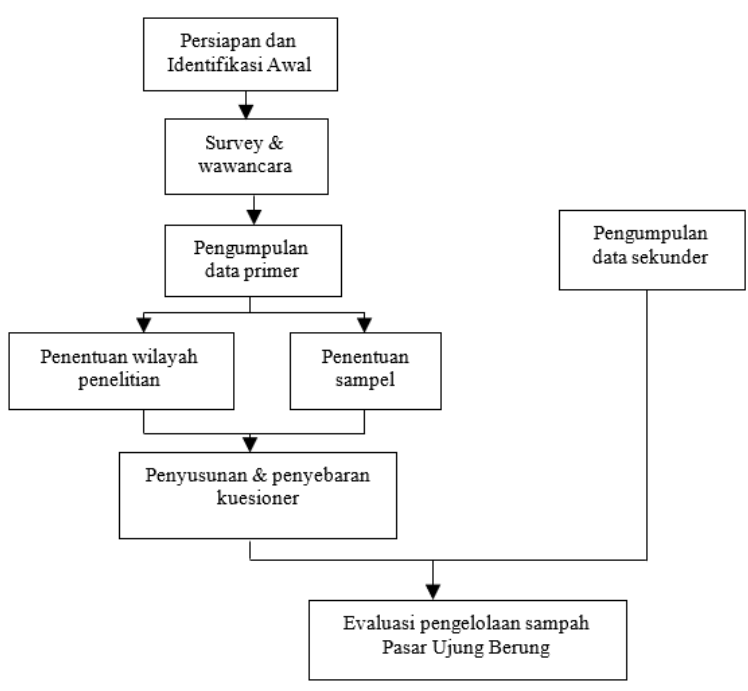

Gambar 1 Diagram Alir Penelitian

\section{Tahap Persiapan dan Identifikasi Awal}

Tahapan ini meliputi studi dan analisis data awal yang diperoleh dari PD Pasar berupa data pedagang di Pasar Ujungberung Bandung. Analisis tersebut dilakukan sebagai dasar dan perencanaan untuk kegiatan sampling.

\section{Populasi dan Sampel}

Untuk menentukan jumlah responden pada saat sampling digunakan persamaan slovin yang dapat dilihat pada persamaan (1) di bawah ini.

$$
\mathrm{n}=\frac{\mathrm{N}}{\mathrm{Ne}^{2}+1}
$$

dimana:

$\mathrm{n}=$ Jumlah sampel / responden

$\mathrm{N}=$ Jumlah populasi.

$\mathrm{e}=$ Persen kelonggaran ketidaktelitian karena kesalahan pengambilan sampel yang masih dapat ditolerir (10\%).

Diketahui bahwa jumlah kios yang aktif digunakan untuk kegiatan jual-beli adalah sebanyak 565 kios, sehingga jumlah sampel/responden adalah:

$$
\mathrm{n}=\frac{565}{565.0,1^{2}+1}=84,96 \mathrm{kios}=85 \mathrm{kios}
$$

Dari data PD Pasar Bermartabat Kota Bandung, diketahui keseluruhan jumlah kios beserta jenis barang yang dijual. Selanjutnya dihitung persentase setiap jenis barang yang dijual terhadap keseluruhan jumlah kios yang ada. Persentase tersebut kemudian digunakan 
untuk menentukan jumlah sampel per tiap jenis barang yang dijual.

Berdasarkan hasil perhitungan diperoleh jumlah sampel yang bervariasi untuk tiap jenis barang yang dijual. Variasi tersebut bergantung pada persentase jumlah tiap jenis barang yang dijual terhadap keseluruhan kios yang ada. Hasil tersebut dapat dilihat pada Gambar 2 berikut ini.

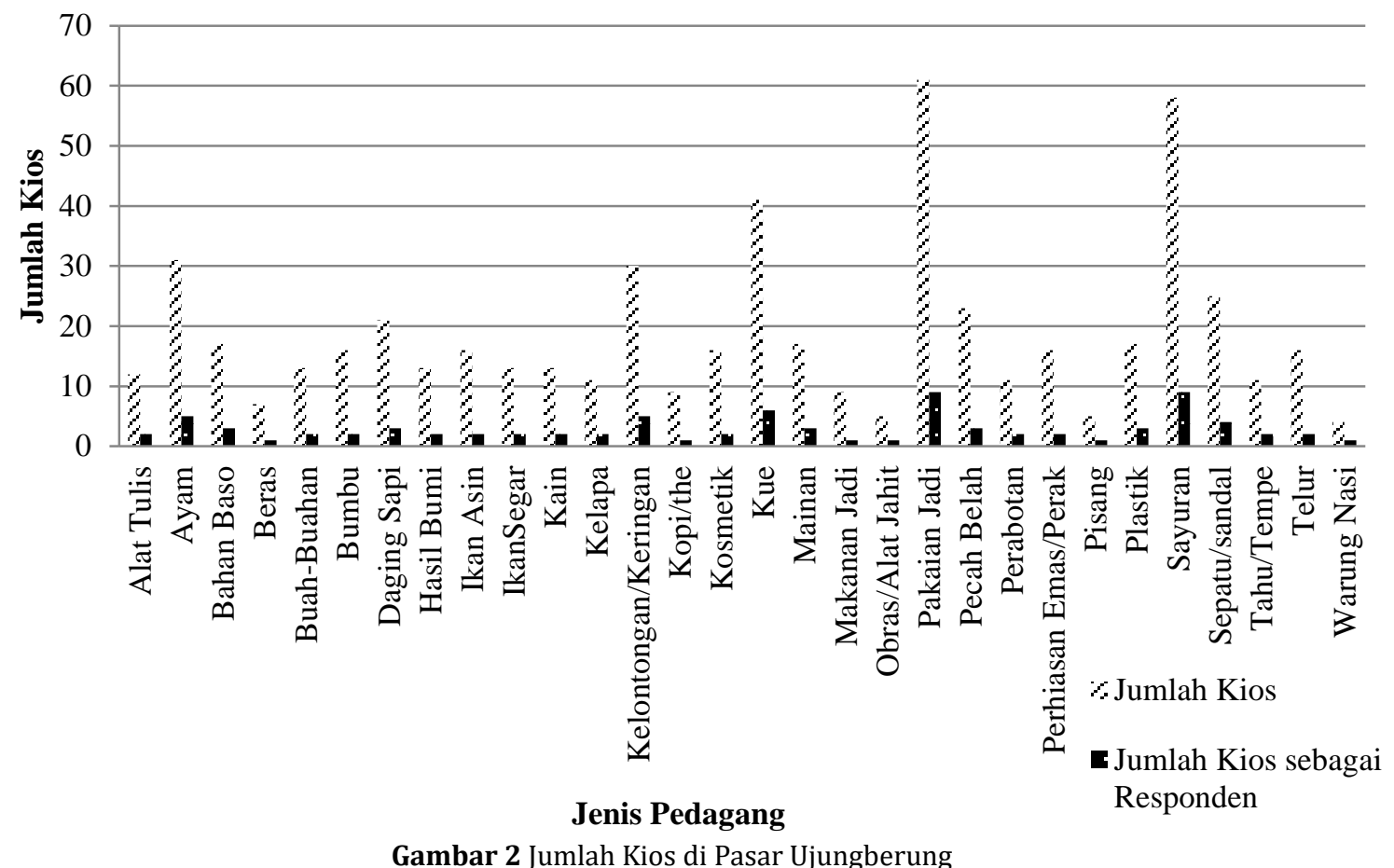

\section{Pengumpulan Data Primer}

Setelah menetapkan jumlah responden maka selanjutnya dilakukan prosedur pengumpulan data primer. Pengumpulan data primer dilakukan dengan kegiatan observasi, sampling, dan kuesioner. Kegiatan observasi meliputi kegiatan survey dan wawancara. Survey dilakukan untuk mengetahui gambaran umum pengelolaan persampahan yang ada sedangkan wawancara dilakukan terhadap petugas kebersihan dan pedagang di Pasar Ujungberung.

Setelah melakukan observasi dilakukan sampling timbulan menggunakan prosedur sampling yang merujuk pada Metode pengambilan dan pengukuran contoh timbulan dan komposisi sampah perkotaan (SNI 19-3964-1995) yaitu selama 8 hari berturut-turut terhadap 85 responden yang mewakili seluruh jenis pedagang di Pasar Ujungberung Bandung. Sampling dilakukan dengan melakukan pengumpulan sampah dari tiap kios untuk selanjutnya sampah tersebut ditimbang, diukur volumenya, dan dipilah berdasarkan komposisinya. Proses pengangkutan sampah dari kios dilakukan secara manual yaitu diangkut/diambil langsung ke setiap kios setelah sampah dikumpulkan selama 24 jam. Peralatan yang digunakan selama sampling adalah timbangan, sampling box, sarung tangan, masker, dan kantong plastik.

Selanjutnya dilakukan penyebaran kuesioner terhadap 85 responden untuk memperoleh berbagai informasi pendukung yang diperlukan dalam proses pengolahan data dan analisis seperti data luas kios, jumlah pekerja/karyawan, jam operasional, serta untuk mengetahui tingkat kepuasan para pedagang terhadap pelayanan kebersihan dari petugas PD Kebersihan Kota Bandung.

\section{Pengumpulan Data Sekunder}

Pengumpulan data sekunder dilakukan sebagai bahan evaluasi terhadap data primer yang diperoleh. Data sekunder yang diperoleh berupa data sarana dan prasarana pendukung pasar dan luas areal pasar di wilayah Kota Bandung. Data sarana dan prasarana diperlukan untuk membantu evaluasi mengenai sistem pewadahan, pengumpulan, penyimpanan, pengangkutan, pengolahan dan pembuangan sampah di Pasar Ujungberung Bandung. Sedangkan data luas areal pasar di wilayah Kota Bandung diperlukan untuk 
memperkirakan keseluruhan timbulan sampah di Kota Bandung.

\section{HASIL DAN PEMBAHASAN Hasil Sampling Timbulan Sampah}

Dari hasil sampling diperoleh timbulan sampah dalam satuan $\mathrm{kg} / \mathrm{hari}$ dan volume sampah dalam satuan $\mathrm{m}^{3}$. Data tersebut kemudian diolah dengan data dari PD Pasar Bermartabat Kota Bandung dan hasil kuesioner berupa jumlah populasi, luas kios, jumlah karyawan, dan jam operasional kios sehingga diperoleh data timbulan dalam $\mathrm{kg} / \mathrm{m}^{2} / \mathrm{hari}$, $\mathrm{kg} / \mathrm{karyawan} / \mathrm{hari}$, dan $\mathrm{kg} / \mathrm{jam}$ operasional/hari. Selain itu juga diperoleh data densitas sampah untuk setiap jenis kios.
Dari hasil pengolahan data diperoleh rata-rata timbulan maksimum $0,74 \mathrm{~kg} / \mathrm{m}^{2} /$ hari pada kios ikan segar, 1,45 kg/karyawan/hari pada kios buah-buahan, dan 0,45 kg/jam operasional/hari pada kios makanan jadi. Sedangkan rata-rata timbulan minimum yang diperoleh adalah $0,004 \mathrm{~kg} / \mathrm{m}^{2} /$ hari pada kios beras, $0,02 \mathrm{~kg} /$ karyawan/hari pada kios hasil bumi (umbi-umbian), dan $0,001 \mathrm{~kg} / \mathrm{jam}$ operasional/hari pada kios hasil bumi (umbiumbian). Sementara untuk nilai rata-rata densitas maksimum adalah $394,31 \mathrm{~kg} / \mathrm{m}^{3}$ pada kios buah-buahan dan rata-rata densitas minimum adalah $4,32 \mathrm{~kg} / \mathrm{m}^{3}$ pada kios plastik. Untuk lebih jelas dapat dilihat pada Tabel 1 berikut

Tabel 1 Timbulan Sampah Rata-rata Selama Sampling

\begin{tabular}{|c|c|c|c|c|c|c|c|c|}
\hline \multirow[b]{2}{*}{ No } & \multirow[b]{2}{*}{ Jenis Pedagang } & \multirow[b]{2}{*}{$\begin{array}{l}\text { Popu- } \\
\text { lasi }\end{array}$} & \multirow[b]{2}{*}{$\begin{array}{l}\text { Respon- } \\
\text { den }\end{array}$} & \multicolumn{4}{|c|}{ Satuan Timbulan (per hari) } & \multirow[b]{2}{*}{$\begin{array}{l}\text { Densitas } \\
\left(\mathrm{kg} / \mathrm{m}^{3}\right)\end{array}$} \\
\hline & & & & $\begin{array}{l}\mathrm{kg} / \mathrm{jenis} \\
\text { pedagang }\end{array}$ & $\mathrm{kg} / \mathrm{m}^{2}$ & $\begin{array}{l}\mathrm{kg} / \text { karya- } \\
\text { wan }\end{array}$ & $\begin{array}{c}\mathrm{kg} / \mathrm{jam} \\
\text { operasional }\end{array}$ & \\
\hline 1 & Alat Tulis & 12 & 2 & 0,130 & 0,006 & 0,065 & 0,010 & 21,590 \\
\hline 2 & Ayam & 31 & 5 & 0,357 & 0,167 & 0,219 & 0,039 & 52,002 \\
\hline 3 & Bahan Baso & 17 & 3 & 0,152 & 0,025 & 0,106 & 0,013 & 14,811 \\
\hline 4 & Beras & 7 & 1 & 0,152 & 0,004 & 0,026 & 0,004 & 17,786 \\
\hline 5 & Buah-Buahan & 13 & 2 & 1,448 & 0,241 & 1,448 & 0,107 & 394,311 \\
\hline 6 & Bumbu & 16 & 2 & 0,230 & 0,307 & 0,140 & 0,030 & 134,667 \\
\hline 7 & Daging Sapi & 21 & 3 & 0,155 & 0,013 & 0,039 & 0,011 & 20,481 \\
\hline 8 & Hasil Bumi & 13 & 2 & 0,018 & 0,024 & 0,018 & 0,001 & 6,886 \\
\hline 9 & Ikan Asin & 16 & 2 & 0,073 & 0,089 & 0,067 & 0,006 & 17,734 \\
\hline 10 & IkanSegar & 13 & 2 & 0,554 & 0,739 & 0,277 & 0,043 & 58,000 \\
\hline 11 & Kain & 13 & 2 & 0,334 & 0,045 & 0,146 & 0,028 & 9,763 \\
\hline 12 & Kelapa & 11 & 2 & 1,040 & 0,132 & 0,520 & 0,079 & 289,169 \\
\hline 13 & Kelontong & 30 & 5 & 0,047 & 0,008 & 0,034 & 0,004 & 4,431 \\
\hline 14 & Kopi/teh & 9 & 1 & 0,143 & 0,024 & 0,072 & 0,011 & 57,156 \\
\hline 15 & Kosmetik & 16 & 2 & 0,369 & 0,036 & 0,109 & 0,043 & 172,747 \\
\hline 16 & Kue & 41 & 6 & 0,134 & 0,022 & 0,097 & 0,013 & 17,920 \\
\hline 17 & Mainan & 17 & 3 & 0,027 & 0,027 & 0,020 & 0,002 & 7,897 \\
\hline 18 & Makanan Jadi & 9 & 1 & 3,167 & 0,264 & 1,056 & 0,452 & 221,793 \\
\hline 19 & Obras/Alat Jahit & 5 & 1 & 0,664 & 0,033 & 0,221 & 0,074 & 47,216 \\
\hline 20 & Pakaian Jadi & 61 & 9 & 0,134 & 0,019 & 0,056 & 0,013 & 14,438 \\
\hline 21 & Pecah Belah & 23 & 3 & 0,146 & 0,024 & 0,066 & 0,011 & 12,431 \\
\hline 22 & Perabotan & 11 & 2 & 0,281 & 0,047 & 0,281 & 0,023 & 32,996 \\
\hline 23 & Perhiasan & 16 & 2 & 0,851 & 0,040 & 0,195 & 0,085 & 82,553 \\
\hline 24 & Pisang & 5 & 1 & 0,599 & 0,100 & 0,299 & 0,046 & 204,453 \\
\hline 25 & Plastik & 17 & 3 & 0,029 & 0,005 & 0,023 & 0,002 & 4,324 \\
\hline 26 & Sayuran & 58 & 9 & 1,228 & 0,581 & 0,882 & 0,111 & 142,771 \\
\hline 27 & Sepatu/sandal & 25 & 4 & 0,216 & 0,034 & 0,164 & 0,019 & 25,043 \\
\hline 28 & Tahu/Tempe & 11 & 2 & 0,110 & 0,018 & 0,055 & 0,009 & 16,396 \\
\hline 29 & Telur & 16 & 2 & 0,170 & 0,023 & 0,170 & 0,013 & 52,697 \\
\hline 30 & Warung Nasi & 4 & 1 & 0,962 & 0,160 & 0,321 & 0,096 & 151,398 \\
\hline \multicolumn{4}{|c|}{ Rata-Rata } & 0,464 & 0,109 & 0,240 & 0,047 & 76,862 \\
\hline \multicolumn{4}{|c|}{ Standar Deviasi } & 0,637 & 0,172 & 0,331 & 0,084 & 96,480 \\
\hline
\end{tabular}



Dari Tabel di atas dapat diketahui rata-rata timbulan sampah per hari akan berbeda-beda tergantung pada satuan timbulan yang digunakan. Rata-rata timbulan sampah terbesar adalah $0,464 \mathrm{~kg} /$ jenis pedagang/hari. Dan nilai terkecil adalah $0.084 \mathrm{~kg} / \mathrm{jam}$ operasional per hari. Dari seluruh rata-rata timbulan dengan menggunakan berbagai jenis satuan timbulan, dapat dihitung jumlah timbulan sampah per hari selama sampling dilakukan. Hasil perhitungan timbulan dapat dilihat pada Tabel 2 berikut ini.

Tabel 2 Timbulan Sampah Selama Sampling

\begin{tabular}{rrcccc}
\hline No & Populasi & Unit & $\begin{array}{c}\text { Timbulan } \\
\text { Rata-Rata }\end{array}$ & $\begin{array}{c}\text { Satuan } \\
\text { Timbulan }\end{array}$ & $\begin{array}{c}\text { Prediksi Total } \\
\text { Timbulan (kg/hari) }\end{array}$ \\
\hline 1 & 565 & pedagang & 0,464 & $\mathrm{~kg} /$ pedagang & 262,160 \\
2 & 3.955 & $\mathrm{~m}^{2}$ & 0,109 & $\mathrm{~kg} / \mathrm{m}^{2}$ & 431,095 \\
3 & 1.130 & karyawan & 0,240 & $\mathrm{~kg} / \mathrm{karyawan}$ & 271,200 \\
4 & 978 & jam & 0,047 & $\mathrm{~kg} /$ jam operasional & 45,966 \\
\hline
\end{tabular}

Sebagai data sekunder diketahui bahwa nilai densitas sampah di TPS II Pasar Caringin Kota Bandung adalah sebesar 0,13 kg/l (Novita, 2002). Dengan menggunakan data densitas tersebut maka dapat diperoleh perkiraan volume sampah yang ditimbulkan selama sampling dilakukan, dengan terlebih dahulu mengkonversi densitas menjadi 130 $\mathrm{kg} / \mathrm{m}^{3}$. Hasil perhitungan volume timbulan menunjukkan volume minimum $0,35 \mathrm{~m} 3 /$ hari dan volume maksimum 3,32 m3/hari. Untuk lebih jelas dapat dilihat pada Tabel 3 berikut ini.

Tabel 3 Prediksi Volume Timbulan Sampah

\begin{tabular}{rrrr}
\hline No & $\begin{array}{c}\text { Timbulan } \\
(\mathrm{kg} / \mathrm{hari})\end{array}$ & $\begin{array}{c}\text { Densitas } \\
\left(\mathrm{kg} / \mathrm{m}^{3}\right)\end{array}$ & $\begin{array}{c}\text { Prediksi Total } \\
\text { Timbulan } \\
\left(\mathrm{m}^{3} / \text { hari }\right)\end{array}$ \\
\hline 1 & 262,16 & & 2,02 \\
2 & 431,10 & 130 & 3,32 \\
3 & 271,20 & & 2,09 \\
4 & 45,97 & & 0,35 \\
\hline
\end{tabular}

Hasil perhitungan menunjukkan bahwa volume sampah yang dihasilkan di Pasar Ujungberung jumlahnya hanya sekitar 0,35$3,32 \mathrm{~m}^{3} /$ hari. Namun berdasarkan hasil observasi di lokasi TPS pasar, seringkali TPS yang berukuran $8 \mathrm{~m}^{3}$ terlihat overload. Berdasarkan hasil wawancara dengan Kepala Pasar Ujungberung, diperoleh informasi bahwa sebagian besar sampah di TPS berasal dari warga sekitar pasar dan para pedagang kaki lima maupun pertokoan di sekitar lokasi pasar. Selain itu di sayap kanan pasar terdapat terminal angkutan kota yang menyebabkan lokasi sekitar pasar semakin ramai dan berpotensi memberikan penambahan timbulan yang masuk ke TPS Pasar.
Berdasarkan hasil kuesioner, para pedagang yang menghasilkan sampah dengan jumlah sangat banyak seperti sampah sayuran seringkali membuang sampahnya di sekitar lokasi kios tanpa memasukkan ke dalam wadah sehingga tidak terdata dalam sampling yang dilakukan.

Sebenarnya TPS pasar yang didirikan sudah memiliki kapasitas yang mencukupi untuk melayani kebutuhan pasar Ujungberung. Namun, dikarenakan lokasi TPS yang strategis dan berdekatan dengan pemukiman maupun fasilitas umum yang lain, maka TPS tersebut tidak lagi berfungsi untuk melayani pasar saja melainkan menjadi TPS umum. Penanganan yang dapat dilakukan untuk memperbaiki kondisi pelayanan di TPS adalah dengan memperbaiki sistem manajemen dan akses TPS. Selain itu dapat dilakukan pendataan terhadap pemukiman maupun pertokoan di sekitar lokasi pasar yang ikut membuang sampah ke TPS pasar sehingga dapat dilakukan perhitungan volume TPS yang dibutuhkan, tentunya dengan adanya penarikan biaya terhadap para pengguna jasa TPS.

\section{Komposisi Sampah}

Komposisi sampah di Pasar Ujungberung Bandung bervariasi bergantung dari jenis barang yang dijual. Pada hasil sampling dilakukan pengelompokkan terhadap komposisi sampah yang ada menjadi 8 kelompok, yaitu sampah organik, kertas, plastik, B3, kain, kaca, kaleng, dan Styrofoam.

Sampah plastik maksimum sebesar 99,7\% dihasilkan oleh kios kain, sampah kertas maksimum sebesar 79,86\% dihasilkan oleh kios kopi/teh, sampah organik maksimum sebesar $100 \%$ dihasilkan oleh kios buah- 
buahan, hasil bumi (umbi-umbian), kelapa, dan pisang, sampah styrofoam maksimum sebesar 1,76\% dihasilkan oleh kios plastik, sampah kaleng maksimum sebesar 1,28\% dihasilkan oleh kios pakaian jadi, sampah kaca maksimum sebesar 9,37\% dihasilkan oleh kios perhiasan, sampah kain maksimum sebesar $51,98 \%$ dihasilkan oleh kios obras/alat Jahit, dan sampah B3 maksimum sebesar 2,47\% dihasilkan oleh kios daging sapi. Untuk lebih jelas dapat dilihat Tabel 4 berikut ini.

Tabel 4 Komposisi Sampah di Pasar Ujungberung

\begin{tabular}{|c|c|c|c|c|c|c|c|c|c|}
\hline \multirow{2}{*}{ No. } & \multirow{2}{*}{ Jenis Pedagang } & \multicolumn{8}{|c|}{ Komposisi Sampah (\%) } \\
\hline & & Plastik & Kertas & Organik & Styrofoam & Kaleng & Kaca & Kain & B3 \\
\hline 1 & Alat Tulis & 49,21 & 49,31 & 0,93 & 0,00 & 0,00 & 0,00 & 0,00 & 0,00 \\
\hline 2 & Ayam & 35,58 & 4,54 & 59,88 & 0,00 & 0,00 & 0,00 & 0,00 & 0,00 \\
\hline 3 & Bahan Baso & 97,21 & 8,22 & 0,00 & 0,00 & 0,00 & 0,00 & 0,00 & 0,00 \\
\hline 4 & Beras & 62,70 & 11,37 & 25,93 & 0,00 & 0,00 & 0,00 & 0,00 & 0,00 \\
\hline 5 & Buah-Buahan & 0,00 & 0,00 & 100,00 & 0,00 & 0,00 & 0,00 & 0,00 & 0,00 \\
\hline 6 & Bumbu & 72,78 & 0,00 & 14,72 & 0,00 & 0,00 & 0,00 & 0,00 & 0,00 \\
\hline 7 & Daging Sapi & 49,92 & 17,98 & 29,63 & 0,00 & 0,00 & 0,00 & 0,00 & 2,47 \\
\hline 8 & Hasil Bumi & 0,00 & 0,00 & 100,00 & 0,00 & 0,00 & 0,00 & 0,00 & 0,00 \\
\hline 9 & Ikan Asin & 69,58 & 23,55 & 6,87 & 0,00 & 0,00 & 0,00 & 0,00 & 0,00 \\
\hline 10 & IkanSegar & 42,56 & 0,95 & 53,95 & 0,00 & 0,32 & 0,00 & 0,00 & 0,00 \\
\hline 11 & Kain & 99,77 & 0,23 & 0,00 & 0,00 & 0,00 & 0,00 & 0,00 & 0,00 \\
\hline 12 & Kelapa & 0,00 & 0,00 & 100,00 & 0,00 & 0,00 & 0,00 & 0,00 & 0,00 \\
\hline 13 & Kelontong & 96,12 & 3,88 & 0,00 & 0,00 & 0,00 & 0,00 & 0,00 & 0,00 \\
\hline 14 & Kopi/Teh & 20,14 & 79,86 & 0,00 & 0,00 & 0,00 & 0,00 & 0,00 & 0,00 \\
\hline 15 & Kosmetik & 20,28 & 47,39 & 19,83 & 0,00 & 0,00 & 0,00 & 0,00 & 0,00 \\
\hline 16 & Kue & 61,77 & 20,86 & 17,37 & 0,00 & 0,00 & 0,00 & 0,00 & 0,00 \\
\hline 17 & Mainan & 17,55 & 3,29 & 0,00 & 0,00 & 0,00 & 0,00 & 0,00 & 0,00 \\
\hline 18 & Makanan Jadi & 10,66 & 0,00 & 89,34 & 0,00 & 0,00 & 0,00 & 0,00 & 0,00 \\
\hline 19 & Obras/Alat Jahit & 19,11 & 21,98 & 6,15 & 0,25 & 0,54 & 0,00 & 51,98 & 0,00 \\
\hline 20 & Pakaian Jadi & 89,46 & 5,55 & 2,82 & 0,04 & 1,28 & 0,86 & 0,00 & 0,00 \\
\hline 21 & Pecah Belah & 43,82 & 52,01 & 0,00 & 0,00 & 0,00 & 0,00 & 0,00 & 0,00 \\
\hline 22 & Perabotan & 71,74 & 10,70 & 10,96 & 0,35 & 0,00 & 0,00 & 0,00 & 0,00 \\
\hline 23 & Perhiasan & 40,82 & 36,58 & 13,21 & 0,02 & 0,00 & 9,37 & 0,00 & 0,00 \\
\hline 24 & Pisang & 0,00 & 0,00 & 100,00 & 0,00 & 0,00 & 0,00 & 0,00 & 0,00 \\
\hline 25 & Plastik & 77,48 & 3,52 & 8,90 & 1,76 & 0,00 & 0,00 & 0,00 & 0,00 \\
\hline 26 & Sayuran & 2,43 & 0,95 & 95,31 & 0,00 & 0,00 & 0,00 & 0,00 & 0,00 \\
\hline 27 & Sepatu/sandal & 49,99 & 33,34 & 16,27 & 0,00 & 0,49 & 0,00 & 0,00 & 0,00 \\
\hline 28 & Tahu/Tempe & 24,39 & 5,64 & 48,76 & 0,00 & 0,00 & 0,00 & 0,00 & 0,00 \\
\hline 29 & Telur & 26,82 & 12,29 & 60,88 & 0,00 & 0,00 & 0,00 & 0,00 & 0,00 \\
\hline 30 & Warung Nasi & 5,14 & 2,52 & 86,59 & 0,00 & 0,00 & 5,75 & 0,00 & 0,00 \\
\hline
\end{tabular}

Kios kain banyak menghasilkan sampah plastik yaitu berupa kantong plastik (keresek) yang digunakan sebagai pembungkus kain. Kain biasa dibeli dalam bentuk gulungan besar dengan pembungkus plastik yang sangat besar. Selain itu plastik yang dihasilkan juga berasal dari botol kemasan plastik dan plastik pembungkus makanan. Kios kopi/teh banyak menghasilkan sampah kertas yaitu berupa kertas dan karton pembungkus kopi/teh. Kios ini juga memiliki jam operasional selama 13 jam dan merupakan tempat yang sering dikunjungi oleh para pedagang dari kios lain. Dengan aktifnya kegiatan jual-beli di kios ini maka jumlah kopi/teh yang digunakan setiap harinya cukup banyak yang berdampak pada besarnya jumlah sampah kertas di kios ini.

Kios buah-buahan, hasil bumi (umbiumbian), kelapa, dan pisang sama-sama menghasilkan $100 \%$ sampah organik. Hal ini 
terjadi karena seluruh barang yang dijual di kios-kios tersebut merupakan bahan organik. Kios-kios tersebut biasanya langsung membuang sampah di sekitar kios tanpa menggunakan wadah (plastik/karung) sehingga tidak ada sampah lain yang dihasilkan selain sampah organik. Sampah organik tersebut antara lain sisa buah yang membusuk dan tidak layak dikonsumsi, kulit singkong dan ubi, ampas dan kulit kelapa, dan sisa pisang yang membusuk.

Kios plastik paling banyak menghasilkan sampah styrofoam. Sampah styrofoam yang dihasilkan berupa wadah pembungkus makanan yang merupakan sisa aktivitas pedagang di dalam kios. Sampah kaleng paling banyak dihasilkan oleh kios pakaian jadi. Kios ini rata-rata memiliki karyawan yang masih muda sehingga lebih tertarik dengan minuman kaleng yang ada di pasaran. Dengan demikian komposisi kaleng minuman yang dihasilkan paling besar dibandingkan kios lainnya. Sampah kaca paling banyak dihasilkan oleh toko perhiasan. Toko perhiasan ini mayoritas karyawannya adalah wanita, dan sampah kaca yang dihasilkan merupakan botol minuman kewanitaan.

Sampah kain terbanyak dihasilkan oleh toko obras/alat jahit. Hal ini terjadi karena toko tersebut tidak hanya menjual perlatan menjahit namun juga melayani obras kain, dengan demikian banyak potongan kain perca yang dibuang. Lain halnya dengan toko kain yang seluruh kainnya untuk dijual sehingga tidak menghasilkan sampah berupa kain. Limbah B3 juga dihasilkan di pasar Ujungberung yaitu berupa baterai. Baterai dihasilkan dari toko daging sapi namun tidak ada hubungannya dengan jenis barang yang dijual. Baterai ini merupakan bekas jam dinding yang dipajang di kios daging sapi tersebut.

Secara umum dapat terlihat pada Tabel diatas bahwa sampah di pasar Ujungberung didominasi oleh sampah plastik, kertas, dan organik. Persentase rata-rata untuk ketiga jenis sampah tersebut secara berturut-turut adalah 42\%, 15,22\%, dan 35,61 \%. Untuk lebih jelasnya, dapat dilihat persen komposisi dari kedelapan jenis sampah yang sudah dikelompokkan sebelumnya pada Gambar 3 berikut ini.

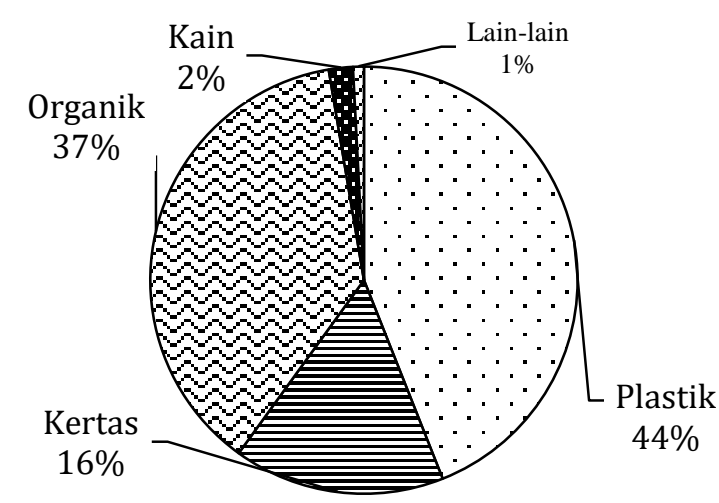

Gambar 3 Komposisi Sampah Pasar Ujungberung

Data komposisi sampah yang diperoleh sangat berguna dalam pemberian alternatif pengolahan sampah yang ada. Dengan jumlah sampah organik yang cukup tinggi yaitu sebesar 35,61 \% maka dapat dilakukan pemanfaatan sampah organik tersebut untuk menjadi kompos. Apalagi sampah organik yang dihasilkan adalah sisa sayur dan buahbuahan yang memiliki kadar air dan kelembaban yang baik untuk proses pengomposan.

Untuk menangani sampah terbanyak yaitu plastik, dapat dilakukan pemilahan di lokasi TPS untuk memisahkan sampah plastik sesuai kelompoknya masing-masing. Sampah plastik yang berupa kemasan air minum dapat dimanfaatkan kembali untuk bahan baku pembuatan botol baru dengan cara menyerahkan botol ke agen pengumpulnya. Dengan demikian dapat sangat mengurangi beban TPS dan TPA juga dapat menghasilkan karena sampah kemasan plastik akan dibeli oleh agen pengumpul. Sampah plastik lainnya yang mendominasi komposisi di Pasar Ujungberung adalah penggunaan kantong keresek sebagai wadah utama dalam kegiatan jual-beli. Sebaiknya dilakukan penerapan peraturan baru yang melarang penggunaan plastik/keresek secara berlebih. Keresek yang sudah ada dapat dimanfaatkan untuk menjadi produk bermanfaat seperti tas yang terbuat dari anyaman plastik dan keresek. Selain itu keresek masih dapat digunakan berulangulang sehingga sebaiknya keresek digunakan seoptimal mungkin sesuai prinsip 3R yang pertama yaitu reduce yang maksudnya adalah mengurangi sampah di sumber. Menurut hasil wawancara dengan pedagang pasar, sudah mulai ada wacana tentang penggunaan kantong kain untuk berbelanja di pasar, namun penerapannya masih sulit. 


\section{Penanganan Sampah}

Berdasarkan hasil kuesioner terhadap 85 responden, diketahui bahwa $31 \%$ pedagang di Pasar Ujungberung tidak pernah menangani sampah yang mereka hasilkan. Mereka cenderung membuang sampah di sekitar kios/tempat mereka berjualan tanpa menggunakan wadah tertentu. Sedangkan $57 \%$ dari pedagang menangani sampahnya dengan cara memasukkannya ke dalam kantong plastik yang disediakan sendiri sehingga memudahkan pengumpulan oleh petugas kebersihan, namun hal ini pun tidak terlalu banyak membantu proses pengumpulan karena kantong plastik tersebut sering kali dibiarkan terbuka sehingga sampah yang ada mudah tumpah dan tercecer. Sisanya sebanyak $9 \%$ responden membuang sampahnya ketempat sampah terdekat di sekitar kios mereka dan 3\% membuang sampahnya sendiri ke TPS. Untuk lebih jelas dapat dilihat pada Gambar 4 berikut ini.

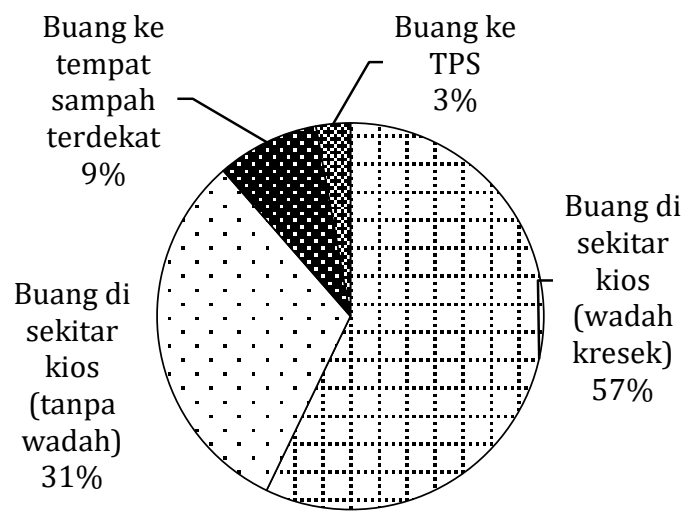

Gambar 4 Penanganan Sampah oleh Pedagang

Pihak PD Kebersihan dan PD Pasar pernah menyebarkan tong/drum di setiap blok pasar sebagai tempat pembungan sampah agar menjadi lebih teratur dan memudahkan pengangkutan ke TPS oleh petugas. Namun tong/drum tersebut tidak pernah bertahan lama karena mudah hilang. Untuk dapat menghasilkan pelayanan kebersihan yang terbaik, seharusnya seluruh pihak yang terlibat baik penghasil sampah maupun pengangkut sampah saling bekerja sama. Sebaiknya setiap kios atau setiap blok kios disediakan wadah untuk menampung sampah dan apabila ingin membuang sampah ke TPS maupun ingin sampahnya diangkut oleh petugas, maka harus menggunakan wadah tersebut. Apabila sampah dibiarkan tercecer di sekitar kios dan ingin dibersihkan oleh petugas penyapu jalan maka harus dikenakan pembayaran ekstra. Hal ini dilakukan agar para pedagang pasar dapat lebih peduli terhadap sampah yang mereka hasilkan.

Selain dari pihak para pedagang, perlu dilakukan evaluasi juga terhadap para petugas kebersihan. Berdasarkan hasil kuesioner, 70\% dari responden beranggapan bahwa jadwal pengumpulan sampah oleh petugas sebaiknya ditambah. Pengumpulan yang hanya satu kali di pagi hari dirasa tidak cukup apalagi aktivitas jual-beli di pasar berlangsung sejak dini hari sampai malam. Para pedagang berharap agar pengumpulan sampah dilakukan 2 kali sehari pada pagi dan sore hari sehingga kondisi kios mereka lebih bersih dan nyaman. Ketidakpuasan pun terjadi apabila hari libur tiba, karena petugas kebersihan akan libur sementara aktivitas di pasar tak mungkin dihentikan, sehingga berdampak pada ketidaknyamanan baik bagi pembeli maupun pedagang setempat. Pengaturan shift yang baik akan sangat bermanfaat untuk menanggulangi permasalahan ini.

\section{KESIMPULAN}

Rata-rata timbulan sampah di pasar Ujungberung Bandung berkisar antara 0,004$0,74 \quad \mathrm{~kg} / \mathrm{m}^{2} /$ hari; $\quad 0,02-1,45$ $\mathrm{kg} / \mathrm{karyawan} / \mathrm{hari}$; dan 0,001-0,45 kg/jam operasional/hari, Jumlah rata-rata timbulan maksimum adalah $0,74 \mathrm{~kg} / \mathrm{m}^{2} /$ hari pada kios ikan segar; $1,45 \mathrm{~kg} /$ karyawan/hari pada kios buah-buahan; dan $0,45 \quad \mathrm{~kg} / \mathrm{jam}$ operasional/hari pada kios makanan jadi. Sedangkan rata-rata timbulan minimum yang diperoleh adalah $0,004 \mathrm{~kg} / \mathrm{m}^{2} /$ hari pada kios beras, $0,02 \mathrm{~kg} / \mathrm{karyawan} /$ hari kios hasil bumi (umbi-umbian), dan $0,001 \quad \mathrm{~kg} / \mathrm{jam}$ operasional/hari pada kios hasil bumi (umbiumbian). Sementara untuk nilai rata-rata densitas maksimum adalah $394,31 \mathrm{~kg} / \mathrm{m}^{3}$ pada kios buah-buahan dan rata-rata densitas minimum adalah $4,32 \mathrm{~kg} / \mathrm{m}^{3}$ pada kios plastik. Variasi timbulan dapat dipengaruhi oleh jenis barang yang dijual di setiap kios, banyaknya aktivitas jual-beli, luas kios, jumlah pekerja di setiap kios, dan jam operasional kios.

Meskipun Pasar Ujungberung merupakan pasar tradisional, komposisi sampah terbesarnya bukan didominasi oleh sampah organik melainkan sampah plastik. Hal ini disebabkan oleh heterogennya Pasar Ujungberung sehingga terdapat 30 jenis barang dagangan mulai dari makanan pokok kingga perhiasan. Dengan demikian sampah berupa plastik dapat mendominasi karena 
masih digunakan sebagai wadah atau kantong pembungkus.

Pada dasarnya sarana TPS Pasar Ujungberung sudah cukup untuk melayani kebutuhan tempat penampungan sampah sementara pasar, namun karena lokasi pasar yang strategis dan berdekatan dengan rumah penduduk, kawasan pertokoan, dan terminal, maka TPS tersebut bukan lagi menjadi TPS pasar, namun digunakan sebagi TPS umum. Dengan demikian kapasitas TPS tidak mencukupi untuk melayani kebutuhan itu semua.

Penanganan sampah di Pasar Ujungberung kurang mendapat peran dari pedagang/pemilik kios. Seringkali sampah dibiarkan di sekitar lokasi kios yang nantinya pun dapat menyulitkan petugas kebersihan dalam proses pengumpulan dan pengangkutan. Meskipun kebersihan Pasar Ujungberung telah dikelola oleh PD Kebersihan namun itu saja tidak cukup karena diperlukan kerja sama yang baik antara petugas kebersihan dan pedagang pasar selaku konsumen untuk menghasilkan pengelolaan sampah yang lebih baik lagi.

\section{DAFTAR PUSTAKA}

Aye, L., Widjaya, E.R. (2006). Environmental and Economic Analyses of Waste Disposal Option for Traditional Markets in Indonesia. Waste Management. 26:11801191.

Chaerul, M. (2019). Performance of Bioplant for Municipal Solid Waste at Jatinangor Campus of Institut Teknologi Bandung. E3S Web of Conference. 148:1-4.

Hartono, D.M., Kristanto, G.A., Amin, S. (2015). Potential Reduction of Solid Waste Generated from Traditional and Modern Markets. International Journal of Technology. 5:838-846.

Matsui, M., Trang, D.T.T., Thanh, N.P. (2015). Estimation of Waste Generation and Recycling Potention from Tradional Market: A Case Study in Hue City, Vietnam. Journal of Environmental Protection. 6:308-320.

Nengse, S. (2017). Pengaruh Penambahan Kompos pada Tanah untuk Mengurangi Genangan di Kelurahan Bulak, Kecamatan Kenjeran, Kota Surabaya. Al Ard: Jurnal Teknik Lingkungan. 2(2):46-52.

Novita, Indriany. (2002). Studi Alternatif Pengelolaan Sampah di Pasar Caringin.
Bandung. Laporan Tugas Akhir, Program Studi Teknik Lingkungan, ITB.

Pribadi, A. (2015). Pemanfaatan Limbah Kertas Koran sebagai Bahan Pengganti Agregat Kasar dalam Campuran Papercrete Serta Aplikasinya untuk Elemen Struktur Ringan dan Non Struktur Ramah Lingkungan. Al Ard: Jurnal Teknik Lingkungan. 1(1):1-10.

Sari, G.L (2017). Kajian Potensi Pemanfaatan Sampah Plastik menjadi Bahan Bakar Cair. Al Ard: Jurnal Teknik Lingkungan. 3(1):613.

Singh, Pratap Rajeev. Singh, Pooja. Araujo, Ademir S. F. Ibrahim, Hakimi. Sulaiman, Othman. (2011). Management of Urban Solid Waste: Vermicomposting A Sustainable Option. Resources, Conversation, and Recycling. 55(7):719729.

Sukresno, H., Hakim, A., Wike, Afandhi, A. (2019). Evaluation of Solid Waste Management Regulation in Minulyo Traditional Market, Pacitan Regency, Indonesia. International Journal of Civil Engineering and Technology. 10(5):806814.

Tchobanoglous, G., Theisen, H., dan Vigil, Samuel A. (1993). Integrated Solid Waste Management, Engineering Principles and Management Issues. Singapore: McGrawHill Book Co.

Ubaidillah, Z., Sumarjo, J., Widianto, E., Hanifi, R. (2018). Pemanfaatan Sampah Plastik dan Organik dalam Pembuatan Paving Block menggunakan Mesin Press. Al Ard: Jurnal Teknik Lingkungan. 4(1):1-10. 